\title{
भारतीय दर्शनेषु मोक्ष प्रक्रिया
}

स्वाति कपिल

सारांश

मोक्ष मानव जीवन का परम लक्ष्य है, इसीलिये मानव के आदि संविधान वेद से लेकर आज तक सभी धर्मशास्त्रीय ग्रन्थों में मोक्ष का चिन्तन प्राप्त होता है। मोक्ष को मुक्ति, कैवल्य, नि:श्रोयस, निर्वाण, अमृत और अपवर्ग आदि नामों से जाना जाता है। विश्व में दो प्रकार की प्रवृत्ति सर्वत्र दृष्टिगोचर होती है प्रथम दुःखों को दूर करने की तथा द्वितीय सुखो को प्राप्त करने प्रवृत्ति। दुःख निवृत्ति भी दो प्रकार की है- प्रथम वर्तमान दुःख की निवृत्ति तथा द्वितीय भावी दुःख की निवृत्ति। इन दोनों प्रकार की प्रवृत्तियाँ ही मोक्ष की विचारधारा की जनक कहलाती है। यह धारणा कि हमें अतिशय सुख प्राप्त हो और दु:खो की निवृत्ति हो वेदों के कारण से ही प्राप्त होती है। भारतीय दर्शन में इस अविद्याकृत प्रपंच से मुक्ति प्राप्त करना ही मोक्ष है। वस्तुतः जीवन में त्याग प्रतिष्ठा का नाम ही मोक्ष है। वासना, तृष्णा, अहंता रूपी बन्धनों से मुक्ति प्राप्त कर आत्म तत्व की और उन्मुख होना ही मोक्ष है। मन पर अधिकार प्राप्त कर लिया जाये और अहंकार तथा इच्छाओं को जड़ कर दिया जाये तो स्थायी परम आनन्द की अनुभूति सम्भव है।

कूट शब्द - भारतीय दर्शन, अविद्या, दु:ख नवृत्ति, बंधन एवं मोक्ष।

मोक्ष मानव जीवन का परम लक्ष्य है, इसीलिये मानव के आदि संविधान वेद से लेकर आज तक सभी धर्मशास्त्रीय ग्रन्थों में मोक्ष का चिन्तन प्राप्त होता है। मोक्ष को मुक्ति, कैवल्य, नि:श्रोयस, निर्वाण, अमृत और अपवर्ग आदि नामों से जाना जाता है।

मोक्ष शब्द मृच्लृ मोक्षणें अथवा मुच्, प्रमोचने मोदने च धातु में अच्, प्रत्यय का योग करने से निष्पन्न होता है। इस प्रकार मोक्ष के दो अर्थ प्राप्त होते हैं प्रथम शरीर के बन्धनों से छुटकारा और द्वितीय अर्थ मोक्ष की भावनात्मक सत्ता का द्योतक है। मोक्ष का अर्थ है छूट जाना (मुच्यते सर्वेभ्यो बन्धनेभ्यो स मोक्ष:) अर्थात् वह अवस्था जिसमें समस्त बन्धनों, दु:खों से छूट जाना होता है, वह मोक्ष कहलाता है। इसी हेतु इसकी मुक्ति संज्ञा भी कहलाती है।

विश्व में दो प्रकार की प्रवृत्ति सर्वत्र दृष्टिगोचर होती है प्रथम दु:खों को दूर करने की तथा द्वितीय सुखो को प्राप्त करने प्रवृत्ति। हम साधारणतः दु:खों की इच्छा न करते हुए अपने सुखों में वृद्धि करना चाहते हैं।

दु:ख निवृत्ति भी दो प्रकार की है- प्रथम वर्तमान दु:ख की निवृत्ति तथा द्वितीय भावी दुःख की निवृत्ति। इन दोनों में भी भावी दु:ख की निवृत्ति अधिक कठिन है, क्योंकि भावी दु:ख वर्तमान कालिक दु:ख की अपेक्षा अधिक बलशाली दृष्टिगोचर होता है। अतः महर्षि पतंजलि ने कहा है कि जो दु:ख भविष्यत् काल में आने वाले हैं वे त्याज्य है (योगदर्शन 2/16)।

'हेयं दु:खमनागतम्'

$$
\text { योगदर्शन }-2 / 16
$$

उक्त दोनों प्रकार की प्रवृत्तियाँ ही मोक्ष की विचारधारा की जनक कहलाती है। यह धारणा कि हमें अतिशय सुख प्राप्त हो और दु:खो की निवृत्ति हो वेदों के कारण से ही प्राप्त होती है। उपनिषदों के युग में तो इसकी पराकाष्ठा उपलब्ध होती है। ईशोपनिषद् में स्पष्टतः कहा गया है वहाँ अर्थात् मोक्षावप्था में मोह और शोक नहीं रहता (ईशोपनिषद- 7) $\left.\right|^{2}$

यस्मिन्सर्वाणि भूतानित्मैवा भूद्विजानतः।

तत्र को मोहः क: शोक: एकत्वमनुभ्यतः

स्वामी दयानन्द ने अपने ग्रन्थ सत्यार्थ-प्रकाश में मोक्ष को इस प्रकार पारिभाषित किया है।

\section{मुज्वयन्ति पृथग्भवन्ति जनो यस्यां सा मुक्ति}

अर्थात् जिसमें प्राणी सम्पूर्ण दु:खो से छूट जाते हैं वही मुक्ति या मोक्ष कहलाता है। दु:ख से छूटकर वह प्राणी सुख को प्राप्त होते हैं और ब्रह्म में रहते हैं।

\section{सभी दर्शनों का मोक्ष के सम्बन्ध में अलग-अलग विचार हैं-}

\section{चार्वाक के अनुसार मोक्ष}

भारतीय दर्शन में जड़वाद का एकमात्र उदाहरण चार्वाक ही है। चार्वाक दर्शन मोक्ष को स्वीकार नहीं करता। मोक्ष का अर्थ है दु:ख विनाश। आत्मा ही मोक्ष को अपनाती है। चार्वाक के अनुसार जब आत्मा की सत्ता ही नहीं है तो मोक्ष की प्राप्ति किसे होगी?

ईशोपनिषद -7

सत्यार्थ प्रकाश, नवम उल्लास, पृष्ठ 162 
अतः मोक्ष का विचार स्वयं खण्डित हो जाता है। चार्वाक के अनुसार देह या आत्मा का विनाश ही मोक्ष है। ${ }^{4}$

\section{'देहच्छेदो मोक्ष:'}

चार्वाको के अनुसार देह का नाश ही मुक्ति है ${ }^{5}$

\section{देहस्य नाशो मुक्तिस्तु।"}

चार्वाको की दृष्टि में कोई भी बुद्धिमान व्यक्ति मृत्यु की कामना नहीं करता अतः मोक्ष को पुरूषार्थ कहना निरर्थक है। चार्वाको ने मृत्यु को ही अपवर्ग माना है। ${ }^{6}$

'मरणमेवापवर्गः।"

\section{जैन दर्शन के अनुसार मोक्ष}

जैन दर्शन में मिथ्या दर्शन को बन्ध का कारण कहा गया है। उसका संवर (अवरोध) कर लेने पर नये कर्मों का अभाव होने से और निर्जरा रूपी कारण के सम्बन्ध से पूर्व कर्मों का विनाश होने पर सम्पूर्ण कर्मों को जो आत्यन्तिक अभाव होता है, समस्त कर्मों से जो मुक्ति प्राप्त होती है, उसे ही मोक्ष कहते हैं। इसीलिए समग्र कर्मों के क्षय को मोक्ष नाम से अभिहित किया गया है।

\section{'बन्धहेत्वभावनर्जराभ्यांकृत्स्नकर्मविप्रमोक्षणं मोक्षः।'}

जिस जीव को मोक्ष प्राप्त हो जाता है, वह अपने नैसर्गिक शुद्ध स्वरूप को प्राप्त कर लेता है। जैन आचार्य कहते हैं कि सूर्य, चन्द्रादि ग्रह तो जाकर लौट आते हैं, परन्तु लोक से परे जो आकाश है उसमें गये हुये मोक्षात्मा आज तक नहीं लौटे।

गत्वा गत्वा निवर्त्ते चन्द्रसूर्यादयो ग्रहाः।

अधापि न निवर्तन्ते त्वलोकाकाशामागताः।।"

जैन दर्शन में मोक्षानुभूति के लिये सम्यक् ज्ञान, सम्यक् दर्शन और सम्यक् चरित्र तीनो को आवश्यक माना गया है।

सम्यक् दर्शन ज्ञान चारित्राणि मोक्ष मार्गः।'

संवर तथा निर्जरा द्वारा जीव कर्मों से पूर्णतः मुक्त होकर मोक्ष को प्राप्त कर लेता है। कर्म-पुद्गल से जीव का मुक्त होना ही उसका मोक्ष है।

सर्वदर्शन संग्रह, प्रो० उमा शंकर शमाभ्तनृपि, पृष्ठ 8 सर्वदर्शन संग्रह, प्रो० उमा शंकर शमीतनृपि, पृष्ठ 9 भारतीय दर्शन, आचार्य बलदेव उपाध्याय, पृष्ठ 78 तत्वार्थ सूत- $10 / 2$ सर्वदर्शन संग्रह, प्रो० उपाशंकर शर्मा स्तृषि, पृष्ठ 145 तत्वार्थ सूत्र- $1 / 1$

\section{बौद्ध दर्शन के अनुसार मोक्ष}

बौद्ध दर्शन में मोक्ष (मुक्ति) के लिए निर्वाण शब्द का प्रयोग किया गया है। निर्वाण को निर्वेद की अवस्था कहा गया है। निर्वाण प्राप्त व्यक्ति अमृतत्व को प्राप्त कर लेता है। बौद्ध दर्शन में निर्वाण का वर्णन दो प्रकार से किया गया है- भावात्मक और अभावात्मक। भावात्मक निर्वाण में परमपद की उपलब्धि प्राप्त होती है, निर्वाण प्राप्त व्यक्ति विमुक्ति रस का आस्वादन करते हैं। अभावात्मक निर्वाण में जन्म-मरण मार्ग समाप्त हो जाते हैं, आशायें मिट जाती हैं, तृष्णा नाम की कोई वस्तु शेष नही रह जाती। अभाव का बिल्कुल अभाव हो जाता है। इसे ही दु:ख का निरोध या निर्वाण कहा गया है।

बुद्ध का वचन है- भिक्षुओं! यह अजात, अमृत, अकृत, असंस्कृत तत्व है, इसीलिये यह जात, नश्वर, कृत और संस्कृत धर्मों का आधार है।

'यस्मा चप्वो भिक्खवे! अत्थि अजातं अमतं मकतं असंरवतं तस्मा जातस्स मतस्स कतस्स संत्वतस्स निस्सरणं पंचाय।

वैभाषिको के अनुसार निर्वाण जीवन की यह अवस्था है जिसकी प्राप्ति सत्य मार्ग के अनुसरण द्वारा की जाती है। यह अकारण, स्वन्त्र, सत् और नित्य है। इसके दो भेद हैं- सोपाधिशेष और निरूपाधिशेष। आस्त्रवक्षय होने पर भी जो अर्हत जीवित रहते हैं उनके पंचस्कन्ध से उत्पन्न अनेक विज्ञान शेष रहते हैं; अतः उनकी दशा का नाम सोपाधिक दशा है। शरीरपात होने पर संयोजन क्षय होने पर समस्त उपाधियों के हटने से निरूपाधिशेष निर्वाण होता है वैभाषिको के अनुसार प्रतिसंख्या निरोध है, अर्थात् विशुद्ध प्रज्ञा के सहारे सांसारिक साश्रव धर्मों तथा संस्कारों का जब अन्त हो जाता है, तब वही निर्वाण कहलाता है। ${ }^{11}$

प्रति संख्यातमनाश्रवा एवं प्रज्ञा गृह्यते तेन प्रज्ञाविशेषेण प्राप्यो निरोध इति प्रतिसंख्या निरोधः।

निर्वाण-नित्य, असंस्कृत धर्म, स्वतन्त्र सत्ता (भाव = वस्तु), पृथग्-भूत सत्य पदार्थ (द्रव्य, सत् है)

द्रव्य: सत्, प्रतिसंख्यानिरोध: सत्यचतुष्ट्य निर्देशनिर्दिष्टत्वातः, मार्ग सत्यवदिति वैभाषिकाः।

निर्वाण के विषय में सौत्रान्तिकों का एक विशिष्ट सिद्धान्त है। इनकी दृष्टि में प्रति संख्या-निरोध और अप्रतिसंख्या निरोध में कोई भेद नहीं है। प्रति संख्या निरोध का अर्थ है- प्रज्ञा-निबन्धन, भाविक्लेशानुत्पत्ति। क्लेशो की निवृत्ति पर ही दुःख अर्थात् संसार

उदानसुत्त- 73

अभिधर्म कोश व्याख्या, यशोमित, पृष्ठ 16

अभिधर्म कोश व्याख्या, यशोमित्र, पृष्ठ 17 
की अनुत्पत्ति अवलम्बित है। क्लेश का उत्पन्न न होना संसार के उत्पन्न न होने का कारण है। इनकी धारणा है कि समाधि के द्वारा ज्ञान-परम्परा की प्रक्रिया के लय हो जाने पर ही मोक्ष की प्राप्ति हो सकती है।

विज्ञानवाद में निर्वाण का रूप शून्य न होकर शुद्ध चित्त है। यह शुद्ध चित्त निर्वाण की अवस्था में प्रपंच की सृष्टि करने वाली सभी प्रकार की बाधाओं से मुक्त हो जाता है। उसे एक दिव्य दृष्टि प्राप्त हो जाती है जिसके द्वारा वह सब में समता या अभेद का साक्षात्कार करता है। विज्ञानवाद के अनुसार योगी दो आवरणो की निवृत्ति द्वारा मोक्ष लाभ प्राप्त कर सकता है। क्लेशावरण तथा झेयावरण। क्लेश मुक्ति का बाधक है। अतः क्लेशावरण की निवृत्ति की निवृत्ति हो जाने पर मोक्ष की प्राप्ति हो जाती है। परन्तु सर्वज्ञता प्राप्त नहीं होती। जेयावरण की निवृत्ति के पश्चात् ही सर्वज्ञता की प्राप्ति होती है। धर्म नैरात्म्य ज्ञान में प्रतिष्ठित होने पर ही ज्ञेयावरण की निवृत्ति सम्भव है। जिसके बाद परमपद की प्राप्ति सम्भव है। योगाचार मत में निर्वाण वस्तुमात के साधारण धर्म की और दुःख रूपता के ज्ञान से प्राप्त होता है। इसी दु:खरूपता के कारण वे इसमें आसक्त नहीं होते और उनका विवेक कभी पराभूत नहीं होता।

महायान पन्थ में बोधिसत्व को उत्कृष्ट बनाने हेतु चार प्रकार के ज्ञान बताये गये हैं। स्वचित्त दृश्यभावना, उत्पादस्थितिभंग विवर्जना, बाध्यभावोपलक्षणता और स्वप्रत्ययार्थज्ञानधिगमाभिन्नलक्षणता। ये चारो प्रकार के ज्ञान निर्वाण प्राप्ति में अत्यधिक सहायक है।

निर्वाण के विषय में नागार्जुन का मत है- 'निर्वाण न तो छोड़ा जा सकता है और न प्राप्त किया जा सकता है। यह न तो उच्छिन्न होने वाला पदार्थ है और न शाश्वत पदार्थ है। यह न तो निरुद्ध है और न उत्पन्न। उत्पत्ति होने पर ही किसी वस्तु का निरोध होता है। यह दोनों से भिन्न है। ${ }^{13}$

अप्रहारणम् अंसप्राप्तं अनुच्छिन्नम् अशाश्वतम्। अनिरूद्धम् अनुत्पन्नम् एतन्निर्वाणमुच्यते।

\section{सर्वदर्शन संग्रह के अनुसार}

सभी संस्कार क्षणिक है, यह स्थिर वासना (विचार) है इसे ही मार्ग जाने। इसे ही मोक्ष कहते हैं। ${ }^{14}$

क्षणिकाः सर्वसंस्कारा इति या वासनास्थिरा।

स मार्ग इति विज्ञेयः स च मोक्षोऽभिधीयते।।

\footnotetext{
13 माध्यमिक कारिका - 25.3

14 सर्वदर्शन संग्रह, प्रा० उमा शंकर शर्मा ऋषि, 88
}

रागादि ज्ञान की परम्परा रूपी वासना के नष्ट हो जाने सें उत्पन्न मुक्ति चारों प्रकार के बौद्धों के लिए कही गयी है ${ }^{15}$

\section{रागादि ज्ञान संतान वासनोच्छेदसम्भवा।}

चतुर्णामपि बौद्धानां मुक्तिरेषा प्रकीर्तिता।

निर्वाण को क्षेम, नैष्ठिक अच्चुत पद ${ }^{16}$, शान्त और शिव ${ }^{17}$ तथा दुलर्भ, शान्त, अजर, अमृत और परंपद बताया है ${ }^{18}$,

\section{क्षेमं पदं नैष्ठिकमच्युतेतत्', शान्तं शिवंसाक्षिकुरूष्व धर्मम्,} दुर्लभ शान्तमजरं परं तद्मृतं पदमं।

भगवान बुद्ध के अन्तिम शब्द यही थे भिक्षुओं! सब संस्कृत धर्म नश्वर है। अप्रमाद के साथ (अमृत निर्वाण) को प्राप्त करो। बौद्धो की दृष्टि में निर्वाण प्रत्येक प्राणी का गन्तत्य स्थान है। वहाँ तक पहुँचने के लिये बौद्ध धर्म में अष्टांगिक मार्ग की व्याख्या की गयी है। इस मार्ग पर चलकर व्यक्ति अपने दुःखों का नाश कर लेता है। इसीलिये समस्त मार्गां में इसे श्रेष्ठ माना गया है। ${ }^{19}$

मग्गानअ्ठगिंको सेट्ठो अर्थात् मार्गाणाम्ष्टागिंको श्रेष्ठः।

\section{सांख्य दर्शन के अनुसार मोक्ष}

सांख्य के अनुसार विश्व में तीन प्रकार के दु:ख पाये जाते हैं। आध्यात्मिक, आधिभौतिक और आधिदैविक। मानव स्वभावतः इन तीनों प्रकार के दु:खों से छुटकारा पाना चाहता है। दु:खो का पूर्ण विनाश मोक्ष से ही सम्भव है। मोक्ष का अर्थ है त्रिविध दु:ख का अभाव। सांख्यसूत्र में कहा गया है कि तीन प्रकार के दु:खो का पूर्ण रूपेण अभाव मोक्ष (अन्तिम पुरुषार्थ) है $\left.\right|^{20}$

त्रिविध दु:खात्यन्तनिवृत्तिरत्यन्त पुरुषार्थः।

दु:खों का पूर्ण विनाश ही मोक्ष है। मोक्ष ही परम पुरुषार्थ या अपवर्ग है सांख्य दर्शन के अनुसार जब तीनों दुःखो का अत्यन्त नाश हो जाता है तो आत्मा की कृतकृत्यता होती है ${ }^{21}$

\section{"अत्यन्तदुःखनिवृत्या कृतकृत्यता।"}

सांख्य दर्शन के अनुसार पुरुष का अज्ञान बन्धन है और स्वरूप का ज्ञान मोक्ष या कैवल्य है। वासतव में सांख्य का पुरुष कभी बन्धन में नहीं पड़ता, इसका बन्धन केवल उसका अज्ञान युक्त

$\begin{array}{ll}{ }_{15} & \text { विवेक विलास- 8/265 } \\ { }_{16} & \text { सौन्दरनन्द- } 16 / 27 \\ { }_{17} & \text { तदैव- } 16 / 26 \\ { }_{18} & \text { बुद्धचरितं- } 12 / 106 \\ { }_{19} & \text { धम्मपद- 20.1 } \\ 20 & \text { सांख्य दर्शन- } 1 / 1 \\ { }_{21} & \text { तदैव- } 6 / 5\end{array}$


होना है। वास्तव में प्रकृति ही बन्धन में पड़ती है, मुक्त होती है और संसरण करती है ${ }^{22}$

\section{संसरति बध्यते मुच्यते च नानाश्रया प्रकृतिः।}

विवेक ज्ञान होने पर पुरुष को भान होता है- मैं यह नहीं हूँ (नाऽस्मि) न तो मैं कोई अचेतन वस्तु हूँ और न अन्तःकरण ही हूँ। बुद्धि में प्रतिबिम्बित चैतन्य भी मैं नहीं हूँ। संसार के समस्त ज्ञेय पदार्थ भी मेरे नहीं है। मैं ममत्वहीन हूँ। तत्वाभ्यास से जब यह ज्ञान सुदृढ़ हो जाता है और निर्विकल्पक ज्ञान व्यक्तिनिष्ठ होकर व्यक्ति की अनुभूति का स्वरूप ग्रहण कर लेता है यही विशुद्ध चैतन्य का स्वरूप है। इसे ही कैवल्य, विवेक या मोक्ष कहा जाता है ${ }^{23}$

\section{एवं तत्वाभ्यासान्नास्मि न मे नाऽहनित्यपरिशेषम्। अविपर्थयाद् विशुद्धं केवलमुत्पद्यते ज्ञानम्।।"}

तत्व ज्ञान हो जाने पर धर्माधर्मादि अकारण हो जाते हैं और दगध बीजों की भांति उनका फल नहीं होता किन्तु संस्कारवशात् कुलाल के चाक के घूमने की तरह वह शरीर धारण किये रहता है ${ }^{24}$

\section{सम्यग् ज्ञानाधिगमाद् धर्मादीनामकारण प्राप्तौ। तिष्ठति संस्कारवशाच्चक्रभ्रमवद् धृत शरीरः।}

जब उक्त संस्कार भी समाप्त हो जाते हैं तब शरीर भी नहीं रह जाता, प्रकृति कृतार्थ हो सदा के लिए इससे निवृत्त हो जाती है और पुरुष कभी नाश न होने वाले तथा अवश्यभावी कैवल्य को प्राप्त होता है $\left.\right|^{25}$

\section{प्राप्ते शरीरभेदे चरितार्थत्वात् प्रधानविनिवृत्तौ। ऐकान्तिकमात्यन्तिकमुभयं कैवल्यमाप्नोति।।}

सांख्याकारिका के अनुसार- ज्ञान से अपवर्ग (मोक्ष) और विपर्यय (अज्ञान) से बन्ध होता है ${ }^{26}$

\section{ज्ञानेन चाउपवर्गो विपर्ययादिष्यते बन्धः।।}

सांख्य सूत्र 3.23 के अनुसार चेतन-अचेतन के भेद साक्षात्कार से मोक्ष की प्राप्ति सम्भ्व है ${ }^{27}$

\section{"ज्ञानान्मुक्ति।।"}

\section{योग दर्शन के अनुसार मोक्ष}

योग दर्शन में मोक्ष को कैवल्य कहा गया है। कैवल्य का अर्थ है- केवली का होना 'केवली भाव कैवल्यम्" अर्थात् अकेलापन का नाम ही कैवल्य है।

महर्षि पंतजलि के शब्दों में पुरुष के योग और उपवर्ग प्राप्ति के पश्चात् महतत्वादि का अपने कारण में लीन हो जाना अथवा चितिशक्ति अर्थात् आत्मा का अपने स्वरूप में स्थित हो जाना ही कैवल्य है ${ }^{28}$

पुरुषार्थशून्यानां गुणानां प्रति प्रसवः कैवल्य स्वरूप प्रतिष्ठा वा चितिशक्तिरिति।"

बुद्धि और पुरुष इन दोनों की जब साम्यभाव से शुद्धि हो जाती है तब वह अवस्था कैवल्यावस्था कहलाती है। ${ }^{29}$

\section{"सत्व पुरुषयो शुद्धिसाम्ये कैवल्यम्।"}

\section{सर्वदर्शन संग्रह के अनुसार}

निरन्तर दीर्घकाल तक चलने वाले यम नियमादि अष्टांग योग का अनुष्ठान करने से तथा परमेश्वर के प्रति अपने सभी कर्मों का अर्पण कर देने से, सत्व और पुरुष की अन्यथा ख्याति के भेद ज्ञान, सभी विघन-बाधाओं से रहित होकर उत्पन्न होती है तथा उसी समय अविद्यादि पंचक्लेश मूलतः समाप्त जाते हैं। इसके साथ-साथ पाप और पुण्य के रूप में जो कर्मों के भण्डार है वे भी जड़ से नष्ट कर दिये जाते हैं तत्पश्चात् निर्लेप पुरुष केवलरूप में अवस्थित होता है, इसे ही कैवल्य कहते हैं जब पुरुष इस प्रकार के सम्बन्ध में मुक्त हो जाता है प्रकृति से पृथक् रूप में अवस्थित होता है, वही तो मोक्ष है ${ }^{30}$

नैरन्तर्य, दीर्घकालानुबन्धि भवन्ति। ततश्च पुरुषस्य निर्लेपस्य कैवल्येना वस्थानं कैवल्यमिति सिद्धम्।"

चित्तवृत्तियों के निरुद्ध होने पर जब चित्त के कर्तापन के अभिमान की निवृत्ति हो जाती है अर्थात् चित्त का यह भाव नहीं रहता कि मैं सुखी हूँ, मैं दुखी हूँ, मैं कर्ता हूँ आदि। इस प्रकार अभिमान की निवृत्ति हो जाती है, जिससे वृत्ति रूप परिणाम होना भी बन्द हो जाता है, तब आत्मा को अपने शुद्ध स्वरू का दर्शन होने लगता है। इसी को आत्म दर्शन और कैवल्य की र्थिति कहते हैं। तब द्रष्टा अपने स्वरूप में भवस्थित हो जाता है।

तदा द्रष्टुः स्वरूपेऽवस्थानम।"

$$
\begin{aligned}
& \text { सांख्यकारिका- } 62 \\
& \text { सांख्यकारिका- } 64 \\
& \text { सांख्यकारिका- } 67 \\
& \text { दतदैव- } 68 \\
& \text { तदैव- } 44 \\
& \text { सांख्यभूत- } 3.23
\end{aligned}
$$

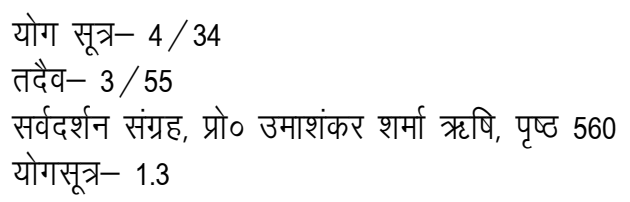




\section{न्यायदर्शन के अनुसार मोक्ष}

बन्धन की अवस्था में आत्मा को सांसारिक दु:खों के अधीन रहना पड़ता है। बन्धन का अन्त ही मोक्ष है। नैयायिकों के अनुसारमोक्ष दु:ख से पूर्ण निरोध की अवस्था है ${ }^{32}$

\section{'तदत्यन्त विमोक्षोऽपवर्गः।'}

मोक्ष को अपवर्ग भी कहते हैं। अपवर्ग का अर्थ है शरीर और इन्द्रियों के बन्धन से आत्मा का मुक्त होना। अज्ञानता के कारण आत्मा शरीर, मन और इन्द्रियों से अपना पार्थक्य नहीं समझती अपितु इन्हें अपना अंग समझने लगती है तथा इन विषयों के साथ तादात्मयता प्राप्त कर लेता है। इसे ही बन्धन कहते हैं। जब तक आत्मा इस बन्धन से ग्रसित रहती है तब तक उसे दुःख से पूर्ण रूपेण मुक्ति प्राप्त नहीं हो सकती। इसलिये मुक्तावस्था में आत्मा के विशेष गुणों- बुद्धि, सुख, दु:ख, इच्छा, द्वेष, प्रयत्न धर्म, अधर्म तथा संस्कार का नाश हो जाता है।

बलदेव उपाध्याय जी के शब्दों में- मुक्त आत्मा में सुख का भी अभाव रहता है, अतः मुक्तावस्था में आनन्द की प्राप्ति नहीं होती $\left.\right|^{33}$

अतः नैयायिकों के अनुसार' मोक्ष एक ऐसी अवस्था है जिसमें आत्मा के केवल दु:खों का ही अन्त नहीं होता अपितु उसके सुखों का भी अन्त हो जाता है। मोक्ष की अवस्था को आनन्दविहिन माना गया है। मोक्ष कहा है | ${ }^{34}$

महर्षि वात्स्यायन ने समस्त दुःखों के अत्यन्त नाश को

\section{तेन दु:खेन जन्मनाउत्यन्त विमुक्ति रपवर्गः।}

यह अमरता की एक अवस्था है। भय निर्मुक्त, अविनश्वर, परमानन्द की प्राप्ति से सदा प्रसन्न यह ब्रह्मा ही कहा जाता है ${ }^{35}$

\section{तदभयमजरममृत्युपदंब्रह्माक्षेमप्राप्तिरिति।}

\section{न्यायसूत्र के अनुसार}

तत्वज्ञान के बाद दु:ख, जन्म, प्रवृत्ति, दोष और मिथ्याज्ञान इन सबका उत्तरोत्तर कारण का क्रमशः विनाश होने पर इस कारण के पूर्व अव्यवहित रूप में विद्यमान कार्य का विनाश होता है और अन्त में अपवर्ग (मोक्ष) की प्राप्ति होती है ${ }^{36}$

दु:खजन्मप्रवृत्तिदोषमिथ्याज्ञानामुत्तरोतराऽप र्यायतदनन्तरा पायाऽपवर्गः।

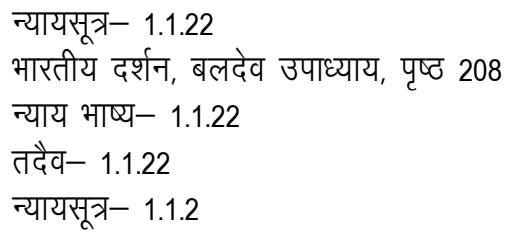

मोक्ष प्राप्ति हेतु न्याय दर्शन में श्रवण, मनन और निदिध्यासन पर बल दिया गया है।

हेतु शास्त्रो का विशेष रूप से आत्माविषयक उपदेशों का श्रवण करना चाहिये।

मोक्ष प्राप्ति के लिये यम और नियम के आचरण से योग अर्थात् चित्तवृत्तियों के निरोध से अध्यात्म शास्त्रों में विवेचित उपायों से आत्मा का संस्कार अर्थात् समाधि लाभ से मोक्ष प्राप्त करना चाहिए । $^{37}$

तदर्थयमनियमाभ्यामात्मसंस्कारों योगच्चाध्यात्म विघ्युपायैः।

न्यायसूत्र के अनुसार- मोक्ष में उसका (इन्द्रिय और अर्थ के आश्रयभूत शरीर का) अभाव होता है ${ }^{38}$

\section{'तद्भावश्चापवर्गे'}

\section{वैशेषिक दर्शन के अनुसार मोक्ष}

अविद्या से बन्धन तथा विद्या से मोक्ष प्राप्त होता है। आत्मा अविद्यावश कर्म करता है तथा कर्म के धर्माधर्म संस्कार अदृष्ट में संचित होते रहते हैं तथा फलोन्मुख होने पर आत्मा के कर्मफल भोगार्थ सृष्टि उत्पन्न होती है। जब तक आत्मा कर्मजाल में फँसा रहता है तब तक उसका बन्धन बना रहता है। ज्ञान द्वारा कर्म का विनाश कर देने पर नये कर्म उत्पन्न नहीं होते तथा संचित एवं प्रारब्ध कर्मों का क्षय होने पर आत्मा का शरीर, इन्द्रिय और मन से आत्यन्तिक वियोग हो जाता है तथा आत्मा अपने शुद्ध रूप में स्थित हो जाता है यही मोक्ष है। महर्षि कणाद के अनुसार- द्रव्य, गुण, कर्म, सामान्य, विशेष और समवाय इन छः पदार्थों के परस्पर साधर्म्य और वैधर्म्य के ज्ञान से धर्म विशेष से अनुभूत हुए तत्व ज्ञान से मोक्ष की प्राप्ति होती है । ${ }^{39}$

धर्म विशेष प्रसूताद् द्रव्यगुण कर्म सामान्य विशेषसमवायाना पदार्थानां साधर्म्य वैधर्म्याभ्यां तत्वनानिश्रेयसम्। तत्वज्ञान से उस (अदृष्ट) का अभाव हो जाता है। महर्षि कणाद के अनुसार- आत्मा में जब तक मिथ्या ज्ञान की स्थिति बनी रहती है तब तक जन्म व मरण के चक्र से मुक्ति प्राप्त नहीं होती। संशयरहित ज्ञान की निश्चयात्मक अवस्था में जब आत्मा स्थित हो जाता है तो उसके मिथ्या ज्ञान रूपी राग-द्वेष विनष्ट हो जाते हैं, जिसके कारण सूक्ष्म शरीर से भी आत्मा का सम्बन्ध नहीं रह जाता। अदृष्ट कर्म भी फल भोग सहित नष्ट हो जाते हैं। इस प्रकार उस कारण की ही समाप्ति हो जाती है, जिससे जन्म मरण रूपी कार्य उत्पन्न हो सके। उस

$\begin{array}{ll}{ }_{37}^{37} & \text { तदैव- } 4 / 2 / 46 \\ { }_{38} & \text { तदैव- } 4 / 2 / 45 \\ { }_{39} & \text { वैशेषिक सूत्र- } 1.1 .4\end{array}$


कारण का संयोग न होने से एक शरीर से दूसरे शरीर में प्रवीष्ट होने की प्रक्रिया का न होना ही मुक्ति अर्थात् मोक्ष है। ${ }^{40}$

\section{तद्भावे संयोगाभावोडप्रादुर्भावश्च मोक्षः।}

\section{मीमांसा दर्शन के अनुसार मोक्ष}

इस जगत् के साथ आत्मा के सम्बन्ध के विनाश का नाम मोक्ष है $\left.\right|^{41}$

\section{प्रपंच सम्बन्ध विलयो मोक्षः।}

सकाम कर्मों से जहाँ पाप-पुण्य के कारण जीव बन्धन में पड़ता है, वही निष्काम धर्माचरण और आत्मज्ञान से पूर्व कर्मों के संचित संस्कार विनष्ट हो जाते हैं, जिससे व्यक्ति जन्म मरण के चक्र एवं दु:खों से निवृत्ति प्राप्त कर मोक्ष की प्राप्ति कर लेता है।

प्रपंच जीव को तीन प्रकार से बाँधता है, भोगायतन शरीर, भोग साधन इन्द्रियाँ, चक्षु आदि, भोग्य शब्दादि विषय है भोग से जब सुख-दु:ख विषय अपरोक्ष अनुभव कहे जाते हैं। उक्त तीनों प्रकार के बन्धनों का आत्यन्तिक विलय ही मोक्ष है। ${ }^{42}$

तेधा हि प्रपंचः पुरुषे बध्नाति भोगायतन शरीरम्, भोग साधनानीन्द्रियाणि भोग्या शब्दादयो विषयाः। भोग इति च सुख-दःख विषयोऽपरोक्षाइनुभव उच्यते। तदस्थे त्रिविधस्यापि बन्धस्यात्यन्तिको विलयो मोक्षः।

मोक्ष के सम्बन्ध में मीमांसा दर्शन में प्रायः तीन मत प्राप्त होते हैं। कुमारिल मत, प्रभाकर मत, अन्य मीमांसको का मत।

\section{1. कुमारिल मत}

कुमारिल भट्ट दु:ख के आत्यन्तिक विनाश और मन के द्वारा आनन्द के अनुभव को मोक्ष अथवा मुक्ति की अवस्था मानते हैं। उनकी दृष्टि में आनन्दानुभूति की स्थिति ही मोक्ष है। ${ }^{43}$

\section{दुःत्वात्यन्तसमच्छेदे सति प्रागात्मवर्तिनः। सुखस्य मनसा भुक्तिर्मुक्तिरूक्ता कुमारिलैः।}

\section{2. प्रभाकर मत}

प्रभाकर मिश्र के अनुसार आत्मा में ज्ञान एवं सुख-दु:खादि अनेक गुण विद्यमान रहते हैं। इन गुणों के विनष्ट हो जाने पर आत्मा अपने स्वरूप में अवस्थित हो जाता है और यही स्थिति मोक्ष है। उनकी दृष्टि में मोक्ष की अवस्था में आत्मा को आनन्दानुभूति नहीं

\footnotetext{
40 तदैव 5.2 .18

${ }^{41}$ शास्त्र दीपिका, डॉ॰ किशोर दास स्वामी, पृष्ठ 264

42 शास्त्र दीपिका, डॉ० किशोर दास स्वामी, पृष्ठ 265

${ }^{43}$ मानमेयोदय, जूर्यनारायण शास्त्री, पृष्ठ 212
}

होती है। प्रभाकर मत में नियोग सिद्धिरेव मोक्षः कहकर मोक्ष को परिभाषित किया है $\left.\right|^{44}$

\section{3. अन्य मीमांसकों का मत}

अन्य मीमांसक नित्य नैमित्तिक कर्मों के करते रहने तथा निषिद्ध और काम्य कर्मों को त्याग देने पर मोक्ष की प्राप्ति होती है। ऐसा करने से जन्म- मरण का चक्र समाप्त हो जाता है। यही मोक्ष है। बिना किसी बाहरी फल की कामना किये हुये कर्त्तव्य बुद्धि से नित्य कर्मों का अनुष्ठान ही मोक्ष है। अतः मुक्ति अनवरत कार्य की दशा है। जिसमें क्रिया को छोड़कर अन्य कल की आकांक्षा रहती ही नहीं है। मोक्ष की दशा में आत्मा को आनन्द की अनुभव नहीं होता। मोक्ष दशा में आत्मा शीरादिको से विच्छिन्न हो जाता है। सब प्रकार के दु:खों का सर्वथा नाश हो जाता है और आत्मा सुख-दु:ख से परे विशुद्ध रूप में विद्यमान हो जाता है। यही मुक्त दशा है जो आनन्द न होने पर भी वांछनीय है।

अन्य दर्शनों में जहाँ अनासक्त कर्म द्वारा मोक्ष वर्णित है, वही मीमांसा दर्शन में कर्मकाण्ड द्वारा मोक्ष प्राप्त करने का तथ्य पिवे चित्त है। मीमांसा दर्शन में कर्म और मोक्ष का अन्योन्याश्रय सम्बन्ध है। अतः काम्य और निषद्ध कर्मों का त्याग मुक्ति के लिए अपेक्षित है। जो आत्मा सांसारिक बन्धनों से मुक्त होना चाहती है, उसे काम्य एवं निषिद्ध कर्मों का सर्वथा परित्याग करना चाहिये। किन्तु नित्य कर्मों में प्रवृत्ति रखनी चाहिए। मोक्ष की यही साधिका है। कर्म के साथ-साथ आत्म ज्ञान का होना भी आवश्यक है। कर्म प्रधान कारण है और आत्मज्ञान सहकारी कारण है। कर्तव्यशास्त्र की दृष्टि से मीमांसा ज्ञान कर्म समुच्चय को मानती है इसीलिये कुमारित ने वेदान्त के अनुशीलन को उपादेय बतलाया है ${ }^{45}$

\section{इत्याहनास्तिक्यनिराकरिष्णुरात्मास्ति तांभाष्य कृदसयुक्त्या।} दृढ़त्वमेतद्विषयः प्रबोधः प्रयाति वेदान्त निषेणवेन।

\section{वेदान्त दर्शन के अनुसार मोक्ष}

शंकराचार्य के अनुसार- आत्मा का अपने यथार्थ रूप में अवस्थान ही मोक्ष है ${ }^{46}$

\section{स्वात्मन्यवस्थानं मोक्षः।}

आचार्य शंकर के अनुसार अविद्या की निवृत्ति ही मोक्ष है ${ }^{47}$ अविद्यापगमयात्वात् ब्रह्मा प्राप्ति फलस्य।

\footnotetext{
44 भारतीय दर्शन, आचार्य बलदिव उपाध्याय, पृष्ठ 334

45 शान्त दीपिका, किशोरदास स्वामी, पृष्ठ 282

46 तैत्तिरीयोपनिषद् शांकर भाष्य। $1 / 11$ विदुपोऽशररीत्वम्।

47 वृहदारण्यकोपनिशद् शांकर भाष्य $1 / 14 / 10$
} 
वही ब्रह्मा की प्राप्ति है। मोक्ष और अविद्या की निवृत्ति एक ही है। अविद्या के नाश होने पर ही मोक्षरूपी फल की उत्पत्ति होती है ${ }^{48}$

\section{फलश्च मोशोऽविद्या निवृत्तिवी।}

मोक्ष न किसी का रूपान्तर है और न किसी का भावान्तर ही वेदान्त परिभाषा में आनन्ददायक ब्रह्मा प्राप्ति और समस्त शोक निवृत्ति को मोक्ष कहा गया है। ${ }^{49}$

\section{आनन्दात्मक — ब्रह्मावाप्तिश्चि मोक्षः शोक निवृत्तिश्च।}

इस प्रकार मोक्ष का स्वरूढ निरतिशय सुखात्मक ब्रह्मा प्राप्ति कहा गया है। अद्वेत वेदान्त में मोक्ष प्राप्ति के दो साधनों का उल्लेख प्राप्त होता है। बहिरंग और अन्तरंग। बहिरंग साधन को साधन-चतुष्ट्य भी कहा जाता है साधन चतुष्टय हैनित्यानित्यवस्तु विवेक, वैराग्य, शमादिषट्क तथा मुमुक्षुत्व अन्तरंग साधन भी श्रवण, मनन, निदिध्यासन तथा समाधि के भेद से चार प्रकार के हैं।

वेदान्त परिभाषा के अनुसार - श्रवण, मनन, निदिध्यासन भी ज्ञान के साधन है। ${ }^{50}$

श्रवण-मनन-निदिध्यासनान्यपि ज्ञान साधनानि।"

वृहदारण्योकोपनिषद् की श्रुति कहती है- आत्मा का दर्शन करना चाहिये। इस प्रकार आत्म-दर्शन को उद्देश्य कर इसका श्रवण करे, निदिध्यासन करें इस वाक्य में श्रवण, मनन तथा निदिध्यासन जी महत्ता को प्रतिपादित किया गया है। ${ }^{51}$

\section{आत्मा वा अरे द्रष्टव्यः श्रोतव्यो मन्तव्यो निदिध्यासितव्यो।}

अद्वैत वेदान्त में मोक्ष को दो भागों में विभक्त किया गया है। सन्देह मुक्ति और विदेह मुक्ति।

\section{सन्देह मुक्ति}

अद्वैत वेदान्त की यह सर्वोच्च उपलब्धि है। सदेह मुक्ति प्राप्त व्यक्ति का शरीर प्रारब्ध कर्मानुसार विद्यमान रहता है; किन्तु वह साधक संसार से दूर रहता है मोह इसे सताता नही, तृष्णा उसे प्रभावित नहीं करती; शोक उसे सताता नहीं: संसार उसे सन्तप्त नहीं करताः ममता उसे बॉधती नहीं। मोक्ष नित्य और अशरीत्व है। मृत्यु के साथ स्थूल शरीर का नाश हो जाता हैः परन्तु कारण

\footnotetext{
48 तदैव, $1 / 4 / 7$

49 वेदान्त परिभाषा, डॉ० गजानन शास्त्री मुसलगांवकर, पृष्ठ 382

50 वेदान्त परिभाषा, डॉ० गजानन शास्त्री मुसलगांवकर, पृष्ठ 382

51 वृहदारण्यकोपनिषद्, $2 / 4 / 5$
}

शरीर जीव के साथ बना रहता है और उन्हें पुनर्जन्म के लिये बाध्य करते है आत्मा और शरीर का तादात्म्य मिथ्या है, भान्ति है, अध्याए है अतः अधिष्ठान भूत आत्म साक्षात्कार से अविद्या की निवृत्ति के साथ शरीर रहने पर भी अशरीरत्व या जीवन्मुक्ति प्राप्त हो जाती है। ${ }^{52}$ तस्मान्मिथ्या प्रत्ययनिमितत्वात् सशरीरत्वस्यसिंद्ध जीवितोऽपि। इस अशरीर को सुख और दुःख र्प्पश नहीं करते। ${ }^{53}$ अशरीरं वावसन्ते न प्रिया प्रिये स्पृशतः।

जीवन्मुक्त को अपने शरीर में कोई आसक्ति नहीं होती क्योकि यह शरीर अमृत बह्मा ही है ${ }^{54}$ अथायमशरीरोऽमृतः ब्रहमैवां।

जीवन्मुक्त पुस्प की हदय ग्रन्थि खुल जाती है और समस्त संशय दूर हो जाते है, और इस मुमुक्षु के समस्त कर्म क्षीण हो जाते है I $^{55}$

\section{भिद्यते हदयग्रन्थिश्दिद्यन्ते सर्व संशया}

क्षीयन्तै चास्य कर्मणि तस्मिन्दृष्टे परावरे।

जीवन्मुक्त प्राणी जीवितावस्था में ही समस्त कर्म बन्धनों को तोड़कर सच्चिदानन्द पर ब्रह्म में विलीन हो जाता है।

\section{विदेह मुक्ति}

प्रारष्ध कर्मो के नष्ट हो जाने पर देहपात के पश्चात् विदेहमुक्ति की प्राप्ति होती है इस शरीर का नाश हो जाने पर भावी शरीर के बन्धन से भी मुक्त हो जाता है। अर्थात् जन्म -मरण रूपी सांसारिक बन्धनों से आत्यन्तिक निवृत्ति प्राप्त होने पर पुनः शरीर धारण नहीं करना पड़ता।

रामानुजार्चाय के अनुसार जीवात्मा का प्राकृत शरीर से सम्बन्ध कर्मकल के कारण होता है। यदि कर्मफल का नाश हो जायें तो शरीर सम्बन्ध की आवश्यकत ही समाप्त हो जायेगी। अतः कर्मो और उनके फलो के आत्यन्तिक उच्छेद को ही मोक्ष कहा गया है।

अतः कर्मणा सम्बदस्य परज्योतिरूप सम्पद्यबन्धनिवृत्तिरूपामुक्तिः स्वेन रूपेणा भिनिष्पत्तिरूच्यते। स्वरूपा विर्भावेत्यभिनिष्पत्ति शब्दों दृश्यते, युक्त्याऽयपर्थो निष्पद्यते इत्यादिषुं।

अज्ञान के विनष्ट होते ही जीवात्मा के अहं का भी विलोप हो जाता है, मुक्तात्मा का शरीर से कोई सम्बन्ध नहीं रहजाता। मोक्ष का यह अभवात्मक रूप है।

रामानुजाचार्य मोक्ष का भवात्मक रूप भी स्वीकार करते है। उनके अनुसार जब तक यह शरीर है, तब तक कर्मचक चलता ही रहेगा और कर्म के पूर्ण विनाश के बिना शरीर का

\footnotetext{
52 वृहदारण शांकर भाष्य $1 / 1 / 4$

53 छान्दोग्योपनिषद् $8 / 12 / 1$

${ }^{54}$ वृहदारण्यकोपनिषद् $4 / 4 / 7$

55 मुण्डकोपनिषद $2 / 2 / 8$
} 
विनाश सम्भव नहीं। प्रकृति के विकारों से आत्मा की मुक्ति हो जाने पर भी जीवात्मा तब तक मुक्त नहीं हो सकता, जब तक ईश्वर का साक्षात्कार नही हो जाता ${ }^{56}$ यदुक्तम् विद्यानिवृत्तिरेव मोक्षः सा च बृह्मविज्ञानादेव भवति इति तदभ्युपगम्यते" उनके अनुसार मुक्ति के लिये सर्वोच्च साधन ईश्वर स्वयं है रामानुजदर्शन में मोक्षप्राप्ति के चार साधन बताये गये हैकर्मयोग, ज्ञानयोग, भक्तियोग और प्रपत्ति। कर्म और ज्ञान भक्ति के सहकारी साधन है। परन्तु ईश्वर कृपा के बिना सांसारिक बन्धनों से मुक्ति पाना सम्भव नहीं है। माध्व सम्प्रदाय में निःसीम आनन्द की मूर्ति भगवान विष्णु के आनन्द की अनुभूति को मोक्ष कहा गया है । $^{57}$

\section{विष्णोर्निरवधिका नन्दसदृशानन्दो मोक्ष इति माध्वाः।}

मुक्ति प्राप्त करने हेतु ईश्वर और जीव में भेद का ज्ञान होना नितान्तावश्यक है। जो ईश्वर कृपा पर निर्भर है विष्णु की कृपा के बिना मोक्ष प्राप्त नहीं होता-जिनकी कृपा पाकर परम दु:ख रूपी इस संसार से लोग मुक्त हो जाते है। दूसरे लोग नहीं इस कर्म के जाल से मुक्त होने की इच्छा रखने वालों को उन परम नारायण का चिन्तन करना चाहिए । $^{58}$

\section{मोक्षश्च विष्णुप्रसादमन्तरेण नलभ्यते।}

यस्य प्रसादात्परमार्तिरूपादस्मात्संसारन्मुच्चतेनापरेण।

नारायणोऽसों परमो विचिन्तयो मुमुक्षुभिः कर्मपाशाद मुष्णात्।

माध्व के अनुसार कर्मक्षय, उत्क्रान्ति, अर्चिरादिमार्ग तथा भोग के भेद से मोक्ष के चार प्रकार है। वल्लभ सम्प्रदाय के अनुसारसांसारिक जड़ता और पीड़ा का परित्याग कर परमानन्द की एकनिष्ठ अनुभूति में निमग्न हो जाना ही मुक्ति है भागवत् के अनुसार अन्यथाभाव को दुःख तथा जड़ता को छोड़कर स्वरूप से आनन्दरूप में स्थित होना ही मुक्ति है ${ }^{59}$

\section{"मुक्तिर्हित्वाऽन्यथाभाव स्वरूपेन व्यवरिथतिः।"}

वल्लभाचार्य ने मुक्ति को दो वर्गों में विभक्त किया है। मर्यादा मुक्ति तथा पुष्टि मुक्ति शास्त्रों के अध्ययन, मनन और चिन्तन, वैदिक वचन में आस्था, आचार विचार की पवित्रता, मुक्ति के लिए सतत् प्रयास से जो मोक्ष मिलता है, उसे मर्यादा मुक्ति कहा जाता है भगवान के चरणों की भक्ति मर्यादा भक्ति है इसमें फलेच्छा बनी रहती है।
ईश्वर अनुग्रह से प्राप्त मुक्ति को पुष्टि मुक्ति कहते हैं। पुष्टि मुक्ति से अभेद बोधन की प्रधान तथा सिद्धि होती है। वल्लाभाचार्य ने मुक्ति के लिए पंच साधनों की उपयोगिता स्वीकार की है। वैराग्य, सांख्य, योग, तप और भक्ति। इसी मार्ग से मोक्ष को प्राप्त करता है।

\section{निष्कर्ष}

निष्कर्षतः हम कह सकते हैं कि भारतीय दर्शन में इस अविद्याकृत प्रपंच से मुक्ति प्राप्त करना ही मोक्ष है। वर्तमान जीवन में भी मोक्ष प्राप्ति का मार्ग बताते हुए कहा गया है कि यदि स्थायी रूप से चित्त और आत्मा को एकाकार कर लिया जाये। मन पर अधिकार प्राप्त कर लिया जाये और अहंकार तथा इच्छाओं को जड़ कर दिया जाये तो स्थायी परम आनन्द की अनुभूति सम्भव है। सांसारिक बाधाओं से विमुखता ही मोक्ष है। वस्तुतः जीवन में त्याग प्रतिष्ठा का नाम ही मोक्ष है। वासना, तृष्णा, अहंता रूपी बन्धनों से मुक्ति प्राप्त कर आत्म तत्व की और उन्मुख होना ही मोक्ष है।

कहा गया है- जिसने अहंकार और काम को जीत लिया, जो मन, वचन और शरीर के विकारों से मुक्त हो गया, जो परपदार्थ को आशाओं से निवृत्त हो गया उसे यही (वर्तमान जीवन) में ही मोक्ष की प्राप्ति हो जाती है । $^{60}$

'निर्जित मदमदनानां, मनोवाक्कायविकाररहितानाम्।

विनिवृत्त पराशानां, इहैवमोक्षः सुविहित्तानाम्।।

वर्तमान परिवेश में योग ही मोक्ष प्राप्ति का एकमात्र साधन है जिससे अंतःकरण को पवित्र कर ईश्वर को प्राप्त किया जा सकता है।

स्वाति कपिल, शोध छात्रा, गुरुकुल कांगड़ी विश्वविद्यालय, हरिद्वार (उत्तराखण्ड)।

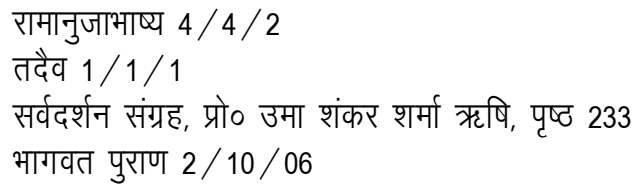

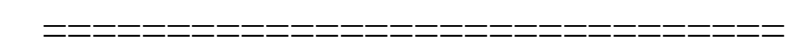

